Article

\title{
Synthesis, Leishmanicidal Activity and Theoretical Evaluations of a Series of Substituted bis-2-Hydroxy-1,4-Naphthoquinones
}

\author{
Morgana V. de Araújo ${ }^{1}$, Patricia S. O. de Souza ${ }^{2}$, Aline C. de Queiroz ${ }^{\mathbf{1}}$, Carolina B. B. da Matta ${ }^{\mathbf{1}}$,
} Anderson Brandão Leite ${ }^{1}$, Amanda Evelyn da Silva ${ }^{1}$, José A. A. de França ${ }^{2}$, Tania M. S. Silva ${ }^{2}$, Celso A. Camara ${ }^{2}$ and Magna S. Alexandre-Moreira ${ }^{1, *}$

1 Laboratory of Pharmacology and Immunity, Institute of Biological Sciences and Health, Federal University of Alagoas, Maceió, AL 57020-720, Brazil;

E-Mails: morgana_vital@hotmail.com (M.V.A.); allycq_farmacia@hotmail.com (A.C.Q.); carolina_damatta@hotmail.com (C.B.B.M.); bioufal@hotmail.com (A.B.L.); Amanda.evelyn13@hotmail.com (A.E.S.)

2 Laboratory of Bioactive Compounds Synthesis, Molecular Sciences Department, Federal Rural University of Pernambuco, Recife, PE 52171-900, Brazil;

E-Mails: patti.soliveira@gmail.com (P.S.O.S.); adoniass@gmail.com (J.A.A.F.); sarmentosilva@gmail.com (T.M.S.S.); ccelso@gmail.com (C.A.C.)

* Author to whom correspondence should be addressed; E-Mail: suzana.magna@gmail.com; Tel./Fax: +55-82-3214-1528.

Received: 8 August 2014; in revised form: 29 August 2014 / Accepted: 9 September 2014 / Published: 22 September 2014

\begin{abstract}
A series of eight substituted bis-2-hydroxy-1,4-naphthoquinone derivatives was synthesized through lawsone condensation with various aromatic and aliphatic aldehydes under mild acidic conditions. The title compounds were evaluated for antileishmanial activity in vitro against Leishmania amazonensis and Leishmania braziliensis promastigotes; six compounds showed good activity without significant toxic effects. The compound with the highest activity was used for an in vivo assay with Leishmania amazonensis.
\end{abstract}

Keywords: naphthoquinones; knoevenagel; bis-2-hydroxy-1,4-naphthoquinones; antileishmanial activity; Leishmania braziliensis; Leishmania amazonensis 


\section{Introduction}

Quinones are a well-known class of compounds with a broad natural distribution; they exhibit a diverse spectra of biological activities, including antitumor [1,2], molluscicidal [3], leishmanicidal [4,5], bactericidal, fungicidal [6,7] and trypanocidal functions [8], and they act as inhibitors of the reverse transcriptase enzyme of HIV-1 [9] and human topoisomerase II [10]. The conjugated 1,4-dicarbonyl or 1,2-dicarbonyl moiety in the most well-known para- and ortho-quinone molecular structures confers specific properties and a reactivity that facilitates participation in redox processes, which are likely related to these substances' mechanisms of action [11,12].

Studies that have considered natural compounds with leishmanicidal activity have highlighted diospyrin, which is a bis-naphthoquinone isolated from Diospyros montana (Ebenaceae) bark; plumbagin isolated from Plumbago species (Plumbaginaceae); and lapachol, which is a prenylated hydroxynaphthoquinone isolated from Tecoma species (Bignoniaceae). These compounds represent a class of quinones with a mechanism of action that involves generating oxygen free radicals, which affect the parasites' defense mechanism and renders the parasites defenseless [13].

Dimeric structures with two 2-hydroxy-1,4-naphthoquinone groups have been studied primarily as intermediates in benzoxanthene derivative synthesis [14-16]; however, a few studies have investigated the biological activities of these compounds. Mazumder and co-workers [17] studied the inhibitory activity of the HIV integrase enzyme using a series of bis-2-hydroxy-1,4-naphthoquinones and reported good results.

In this study, a series of bis-2-hydroxy-1,4-naphthoquinones (bis-lawsones) were synthesized using a simple and quick method. These compounds were evaluated in vitro for antileishmanial activity against Leishmania amazonensis and Leishmania braziliensis promastigotes. The most active compound was used for an in vivo assay with Leishmania amazonensis.

\section{Results and Discussion}

Compounds 3a-h (Scheme 1) were obtained in good yields from a condensation reaction between lawsone with the corresponding aldehyde using $\beta$-alanine and acetic acid catalysis in an inert atmosphere at $50{ }^{\circ} \mathrm{C}$. The compounds $\mathbf{3 b}$ and $\mathbf{3 c}$ obtained from the aliphatic aldehydes $\mathbf{2 b}$ and $\mathbf{2 c}$ showed lower yields due to the formation of the corresponding alkene byproducts through a condensation side reaction that yielded the corresponding 2-alkenyl derivative $[15,16]$.

Scheme 1. Synthesis of compounds $\mathbf{1}-\mathbf{3 h}$.

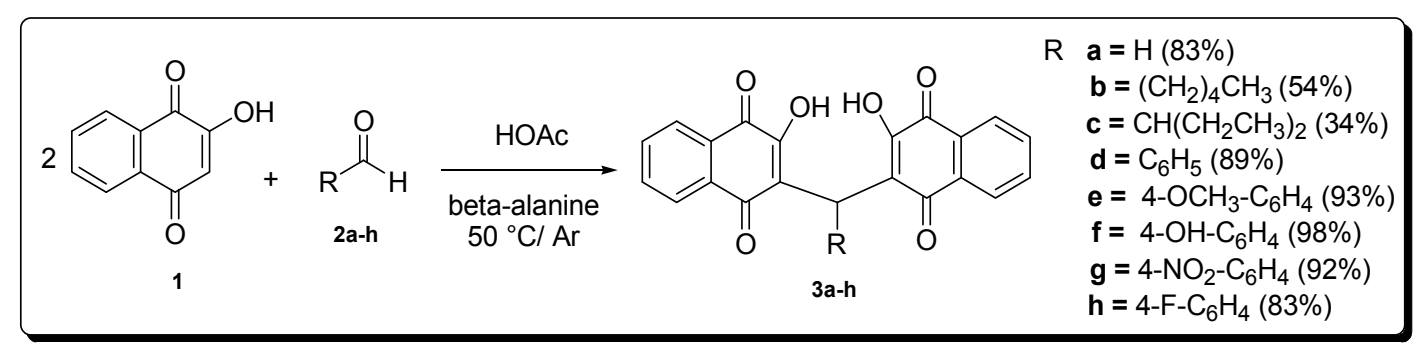

Primarily, the bis-lawsone analogs' cytotoxicity was determined using the MTT method [18] and J774 cell line. The host cells were treated with bis-lawsone analogs and compared with the vehicle 
(DMSO). Table 1 shows the results for the bis-lawsone analogs and pentamidine (reference drug) experiments. The compounds $\mathbf{3 c}$ and pentamidine showed the same deleterious activity to the host cell, as evidenced by the MTT assay, which presented the maximum cytotoxicities $71.7 \% \pm 3.8 \%$ and $78.0 \% \pm 3.8 \%$ as well as $\mathrm{LC}_{50}$ values at $67.4 \pm 2.1$ and $73.0 \pm 6.0 \mu \mathrm{M}$, respectively. After $48 \mathrm{~h}$ of incubation, the other compounds did not affect the $\mathrm{J} 774$ cell line viability at $100 \mu \mathrm{M}$.

Table 1. Determination of the cytotoxicity of bis-lawsone analogs $\mathbf{3 a}-\mathbf{h}$ against macrophages (MTT assay).

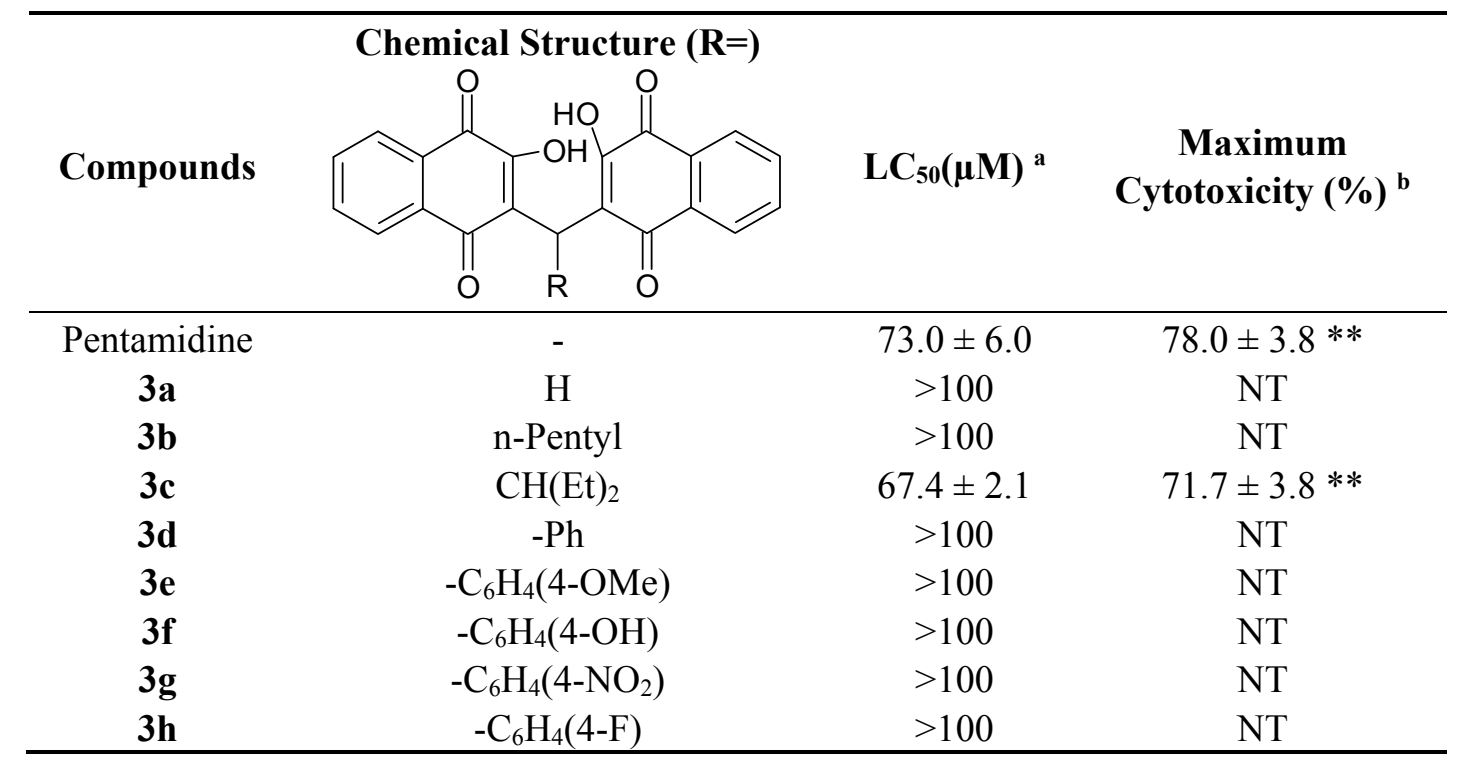

a Lethal Concentration $50\left(\mathrm{LC}_{50}\right)$ calculated by concentration-response curves toxic, using as maximal concentration $100 \mu \mathrm{M} ;{ }^{\mathrm{b}}$ Mean \pm standard error of the mean maximum cytotoxicity in triplicates of a representative experiment; The values of maximum effect were considered significant when $* * p<0.01$ compared to the DMSO group; NT: substance presents no significant lethal activity to cell until the concentration of $100 \mathrm{M}$ in compared to DMSO group.

Theoretical toxicity analysis was performed using the OSIRIS program [18] to analyze their overall drug score and drug-likeness potential as well as toxicity risks (mutagenic, irritant, tumorigenic and reproductive effects) [19]. Comparing the compounds $\mathbf{3 a}-\mathbf{h}$ to the available drugs currently used for the treatment of leishmaniasis, the results show that the bis-lawsone derivatives had no toxicity effects (Figure 1). Except 3c, these results are consistent with the MTT assay results (Table 1). Notably, the toxicity predicted herein is neither a fully reliable toxicity prediction nor a guarantee that these compounds are completely free of a toxic effect, however, the data reinforce the promising profiles for these compounds, which were also detected in vitro, for further experimental investigation. Further, the bis-lawsone analogs' drug-like profiles (drug likenesses and drug-score values) were determined using the OSIRIS program (Figure 2).

The OSIRIS program calculates the drug-likeness based on a list of about 5300 distinct substructure fragments created from 3300 traded drugs as well as 15,000 commercially available chemicals, yielding a complete list of all available fragments with associated drug-likeness. A positive value states that the molecule contains predominately fragments which are frequently present in commercial drugs, so the bis-lawsone analogs do not present these fragments. The drug score already combines drug-likeness, cLogP, $\log \mathrm{S}$, molecular weight and toxicity risks in one handy value that may be used to 
judge a compound's overall potential to qualify as a drug. Thus, it was found that 3a showed the highest drug score among all synthesized analogs.

Figure 1. In silico toxicity risk (tumorigenic, irritant and reproductive effects) for lawsone dimers. Theoretical toxicity risks calculated using the Osiris program. The toxicity profile scale for the side effects included low (1), medium (0.8) and high (0.6).

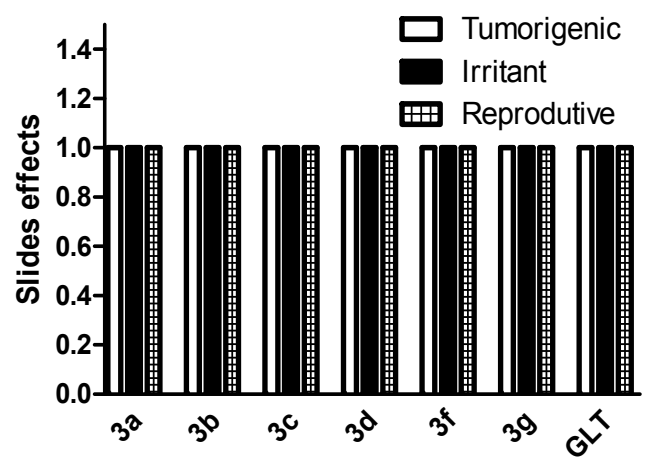

Figure 2. In silico comparison of the drug-like profile (drug-likeness (A) and drug score values (B)) for the bis-lawsone analogs and glucantime (GLT). These parameters were calculated using the Osiris program as described in the Experimental Section.

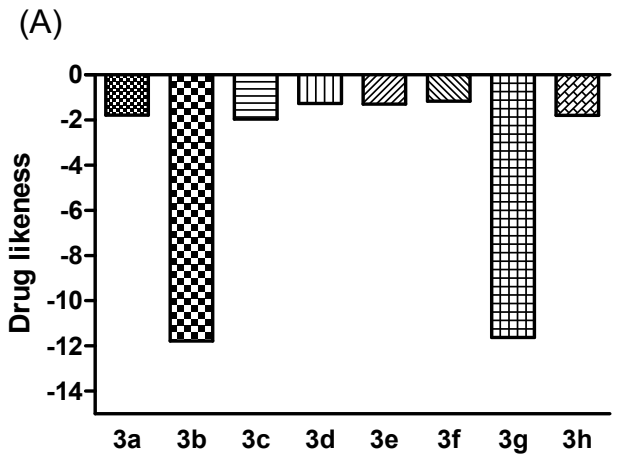

(B)

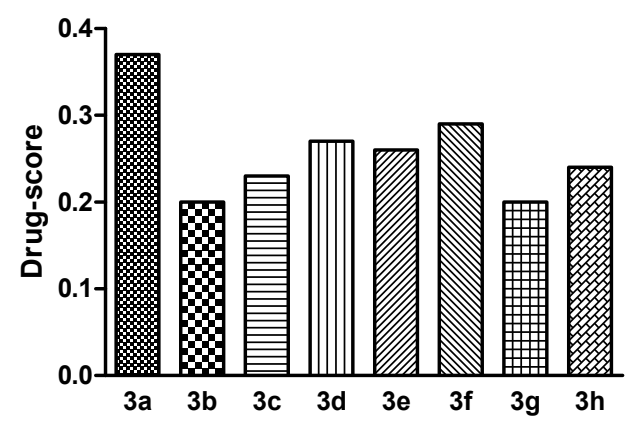

To establish the leishmanicidal profile, the bis-lawsone analogs were evaluated in vitro against the forms of L. amazonensis and L. braziliensis. Pentamidine was used as reference drug in the in vitro tests to evaluate leishmanicidal activity because glucantime (meglumine antimoniate) is not active against promastigote forms. As a parameter for antileishmanial activity, the maximum effect and IC $_{50}$ value (i.e., the sample concentration that reduces survival/viability of the parasites by 50\%) were used (Table 2). As shown, the compounds 3a and 3c were highly active against both Leishmania species, presenting the effects $72.8 \% \pm 1.0 \%$ and $75.3 \% \pm 1.3 \%$ against L. amazonensis and killed 
promastigotes of L. braziliensis in the proportion of $88.4 \% \pm 0.9 \%$ and $90.4 \% \pm 0.7 \%$, respectively. In addition, 3b, 3e, 3f, $\mathbf{3 g}$ and $\mathbf{3 h}$ exhibited high antileishmanial activities against L. braziliensis promastigotes with the maximum effects $93.0 \% \pm 0.1 \%, 61.6 \% \pm 7.5 \%, 91.7 \% \pm 0.3 \%, 91.7 \% \pm 1.3 \%$ and $88.7 \% \pm 0.3 \%$, respectively. Moreover, the bis-lawsone analogs 3a (IC50 value $0.9 \pm 0.08 \mu \mathrm{M}), 3 \mathbf{b}$ (IC50 value $5.2 \pm 0.1 \mu \mathrm{M}), \mathbf{3 e}\left(\mathrm{IC}_{50}\right.$ value $\left.0.9 \pm 0.04 \mu \mathrm{M}\right)$ and $\mathbf{3 h}\left(\mathrm{IC}_{50}\right.$ value $\left.0.8 \pm 0.03 \mu \mathrm{M}\right)$ were as potent as pentamidine (with the efficacy $91.0 \% \pm 0.1 \%$ and $\mathrm{IC}_{50}$ value $0.8 \pm 0.06 \mu \mathrm{M}$ ) for this Leishmania species. In contrast, the derivative 3d did not present activity against promastigote forms of L. braziliensis until $100 \mu \mathrm{M}$; however, it showed a considerable effect $(85.0 \% \pm 3.8 \%)$ and great potency ( $\mathrm{IC}_{50}$ value $0.3 \pm 0.1 \mu \mathrm{M}$ ) against $L$. amazonensis. The compounds $\mathbf{3 a}$ and $\mathbf{3 e}$ were more selective against $L$. braziliensis, presenting $\mathrm{IC}_{50}$ values to this specie 10 times lower than $\mathrm{IC}_{50}$ value to L. amazonensis. On the contrary, compounds $\mathbf{3 c}$ and $\mathbf{3 d}$ were more selective to L. amazonensis in comparation to L. amazonensis. On the other hand, the other compounds showed similar activities against both species of Leishmania tested.

Table 2. Leishmanicidal effect of bis-lawsone analogs $\mathbf{3 a}-\mathbf{h}$ against the growth of promastigotes of L. amazonensis and L. braziliensis.

\begin{tabular}{|c|c|c|c|c|c|}
\hline \multirow[b]{2}{*}{ Compounds } & \multirow{2}{*}{ Chemical Structure $(\mathrm{R}=)$} & \multicolumn{2}{|c|}{ L. amazonensis } & \multicolumn{2}{|c|}{ L. braziliensis } \\
\hline & & $\mathrm{IC}_{50}(\mu \mathrm{M})^{\mathrm{a}}$ & $\begin{array}{c}\text { Maximum Effect } \\
(\%)^{b}\end{array}$ & $\mathrm{IC}_{50}(\mu \mathrm{M})^{\mathrm{a}}$ & $\begin{array}{c}\text { MaximumEffect } \\
\text { (\%) }^{\mathrm{b}}\end{array}$ \\
\hline Pentamidine & - & $2.3 \pm 0.8$ & $85.4 \pm 0.4 * *$ & $0.8 \pm 0.06$ & $91.0 \pm 0.1 * *$ \\
\hline $3 a$ & $\mathrm{H}$ & $71.0 \pm 1.1$ & $72.8 \pm 1.0 * *$ & $0.9 \pm 0.08$ & $88.4 \pm 0.9 * *$ \\
\hline $3 b$ & $n$-Pentyl & $5.2 \pm 0.1$ & $57.2 \pm 3.8 * *$ & $5.2 \pm 0.1$ & $93.0 \pm 0.1 * *$ \\
\hline $3 c$ & $\mathrm{CH}(\mathrm{Et})_{2}$ & $0.4 \pm 0.1$ & $75.3 \pm 1.3 * *$ & $34.7 \pm 4.3$ & $90.4 \pm 0.7 * *$ \\
\hline $3 d$ & $\mathrm{Ph}$ & $0.3 \pm 0.1$ & $85.0 \pm 3.8 * *$ & $>100$ & NT \\
\hline $3 e$ & (4-OMe)Ph & $>100$ & $44.6 \pm 2.4 * *$ & $0.9 \pm 0.04$ & $61.6 \pm 7.5 * *$ \\
\hline $3 f$ & $(4-\mathrm{OH}) \mathrm{Ph}$ & $68.7 \pm 15.1$ & $55.4 \pm 4.7 * *$ & $38.7 \pm 2.0$ & $91.7 \pm 0.3 * *$ \\
\hline $3 g$ & $\left(4-\mathrm{NO}_{2}\right) \mathrm{Ph}$ & $7.7 \pm 1.2$ & $55.6 \pm 3.2 * *$ & $2.8 \pm 0.1$ & $91.7 \pm 1.3 * *$ \\
\hline $3 \mathrm{~h}$ & $(4-\mathrm{F}) \mathrm{Ph}$ & $0.6 \pm 0.2$ & $51.0 \pm 5.5 * *$ & $0.8 \pm 0.03$ & $88.7 \pm 0.3 * *$ \\
\hline
\end{tabular}

${ }^{a}$ Inhibitory Concentration $50\left(\mathrm{IC}_{50}\right)$ was calculated by concentration-response curves toxic and expressed as mean \pm standard error of the mean, using as maximal concentration $100 \mu \mathrm{M}$; ${ }^{\mathrm{b}}$ Maximum Effect (ME) is expressed as mean \pm standard error of maximum toxicity average of triplicates of a representative experiment; The values of maximum effect were considered significant when $* * p<0.01$ compared to the $0.1 \%$ DMSO group; NT: substance presents no significant inhibitory activity for the parasite to the concentration of $100 \mathrm{M}$ compared to DMSO group.

These results indicate a correlation between the leishmanicidal activity and the presence of an alkyl side-chain moiety with a hydrophobic character for the compounds in the series $\mathbf{3 a}-\mathbf{c}$. The compounds with the non polar groups generally exhibit lower activities (Table 2); however, the exception to this trend is the compound 3d, likely due to an oxidative metabolic pathway at the free phenyl ring 4-position. The capacity for further oxidation exhibited by the derivative $\mathbf{3 f}$ with a free $p$-hydroxyl seems to support this assumption. Moreover, the electron-withdrawing substituents in the phenyl ring, as demonstrated for $\mathbf{3 h}$, seems more selective compared with a 4-methoxy donor (3e) in L. amazonensis; both show a similar profile in $L$ brasiliensis. 
Considering the in vitro results, the compound 3a was also used to evaluate the in vivo leishmanicidal activity against L. amazonensis. Glucantime was used as control in thein vivo assay, as this reference drug is the first choice treatment for leishmaniasis and has a lower toxicity to mice, killing a lesser number of animals compared to pentamidine. Glucantime can also be administrated by intraperitoneal route, unlike pentamidine that is just administrated by intravenous route.

Intraperitoneal treatment with $\mathbf{3 a}$ at $30 \mu \mathrm{mol} / \mathrm{kg} / \mathrm{day} \times 28$ days decreased the lesion size for the infected ear on the third week after the treatment began (Figure 3); it did not decrease the parasite load in the infected ear and draining lymph node, similar to the glucantime treatment at same dose (Figure 4). The effect on the lesions obtained with 3a treatment can be due to a possible immunomodulatory or anti-inflammatory activity of the analogue as well because there was a decrease in virulence of the parasite during treatment, although there isn't reduction in parasite burden. In addition, in vivo treatment with 3a neither induced a change in the spleen weight (Figure 5) nor altered alanine aminotransferase (ALT), aspartate aminotransferase (AST), creatinine (CREA) and urea (Figure 6) in the animals' plasma.

Figure 3. In vivo efficacy of 3a and glucantime treatments $(30 \mu \mathrm{mol} / \mathrm{kg} / \mathrm{day} \times 28$ days, i.p. $)$ (A) in BALB/c mice infected wituh L. amazonensis. The lesion sizes were monitored weekly (non-infected control (B), infected control (C), glucantime (D) and 3a (E)). The values are the mean lesion sizes for five mice from each group, and the bars represent the standard error of the mean.
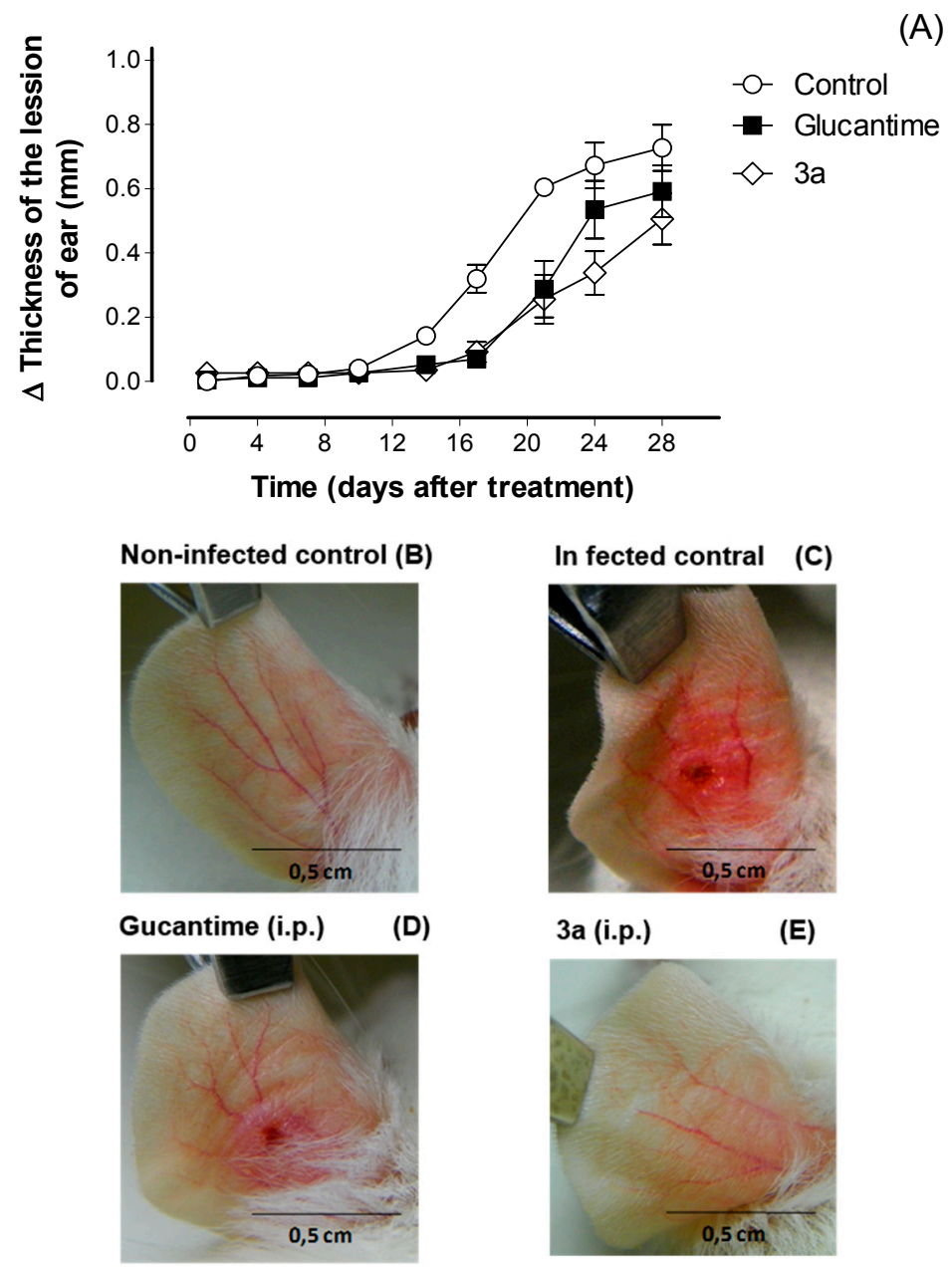
Figure 4. Parasite burden throughout the course of the 3a and glucantime treatments $\left(30 \mu \mathrm{mol} / \mathrm{kg} / \mathrm{dia} \times 28\right.$ days, i.p.) in BALB/c mice infected with L. amazonensis. (A) $\log _{10}$ of the parasites load in the infected ear; (B) $\log _{10}$ of the parasites load in the draining lymph node. The infected ear and draining lymph node parasite loads were determined using a quantitative limiting-dilution assay. Values are the mean parasites load for five mice from each group, and the bars represent the standard error of the mean.

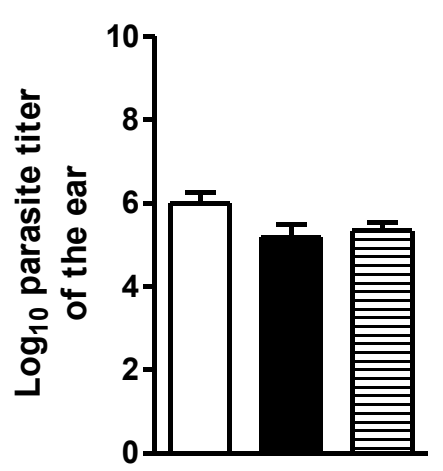

(A)

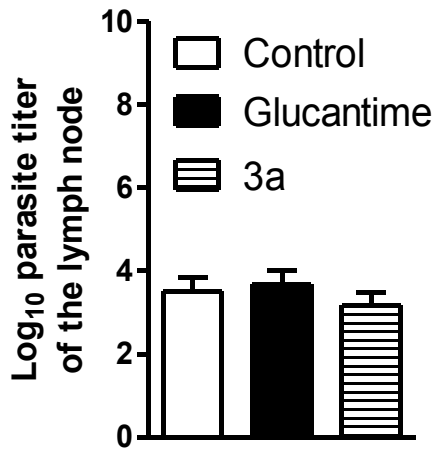

(B)

Figure 5. The in vivo effect from the 3a and glucantime treatments $(30 \mu \mathrm{mol} / \mathrm{kg} /$ day $\times 28$ days, i.p.) on the spleen weights of the BALB/c mice infected with L. amazonensis. The spleen weight was determined on last day of treatment. The values are the mean lesion size for five mice from each group, and the bars represent the standard error of the mean.

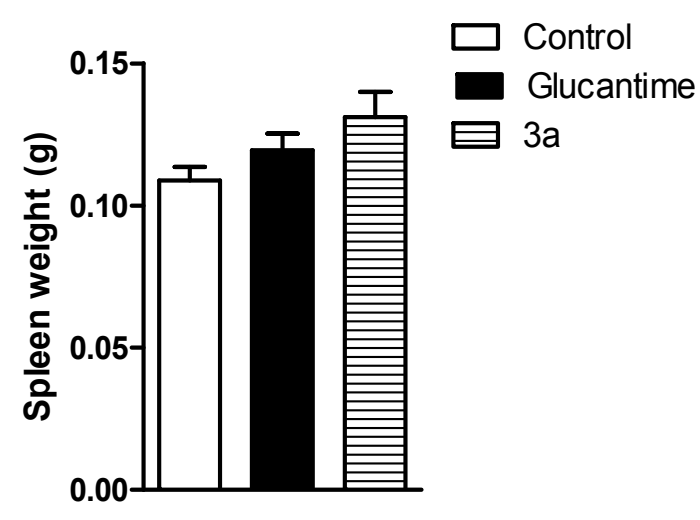

Among the known biological activities of compounds with a quinone structure, these substances stand out for their antiprotozoal activity. For example, three synthesized naphthofuranquinone C-allyl lawsone derivatives were active against Trypanosoma cruzi trypomastigotes [8]. When used as therapeutic agents, quinonoidal ligand cytotoxic activity operates through various mechanisms, such as redox cycling, intercalation, inducing DNA strand breaks, arylation, alkylation via quinone methide formation and free radical generation [20].

Leishmaniasis is a public health issue and is among the five most prevalent parasitic diseases worldwide. According to the World Health Organization, anthropozoonosis leishmaniasis affects 12 million people with an annual incidence of approximately 2 million new cases, and most occur in undeveloped countries such as Brazil. The standard leishmaniasis treatment includes antimonials, amphotericin B and pentamidine, but these compounds are often associated with serious side effects. [21] Discovery and development of new therapeutic agents is a priority due to the increasing prevalence of 
drug resistance in Leishmania, toxicity towards currently used drugs and the lack of an effective prophylactic vaccine against the disease [22].

Figure 6. The in vivo effect from the $3 \mathbf{a}$ and glucantime treatments $(30 \mu \mathrm{mol} / \mathrm{k} /$ day $\times 28$ days, i.p.) on the serum ALT (A), AST (B), creatinine (C) and urea (D) levels in BALB/c mice infected with L. amazonensis. The lesion sizes were monitored weekly. The values are the mean lesion size for five mice from each group, and the bars represent the standard error of the mean.

(A)

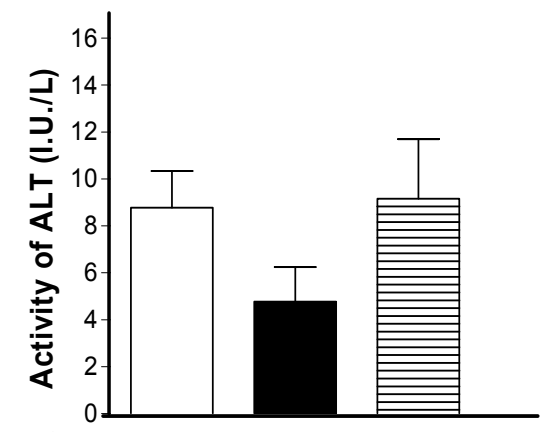

(C)

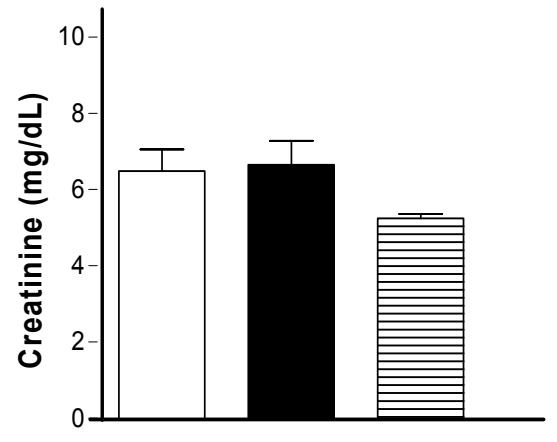

(B)

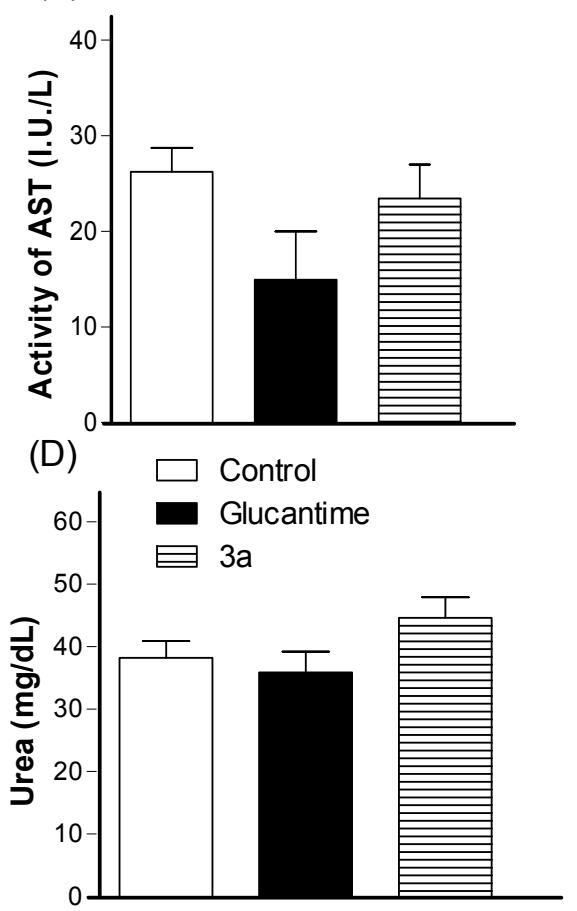

Naphthoquinone antileishmanial activity has also been observed. Lapachol, isolapachol and dihydrolapachol present significant activity; isolapachol acetate was the most active against promastigotes, with $\mathrm{IC}_{50}$ values of $1.6 \mu \mathrm{g} / \mathrm{mL}$ and $3.4 \mu \mathrm{g} / \mathrm{ml}$ for L. amazonensis and L. braziliensis, respectively [23].A series of monomeric and dimeric naphthoquinones with potential for treating Leishmania infections was identified in vitro against extracellular L. donovani, L. infantum, L. enriettii and $L$. major promastigotes. Several naphthoquinones were actives at microgram concentrations (EC50 $0.9-17.0 \mu \mathrm{g} / \mathrm{mL}$ ). When tested against a panel of human cancer cell lines and murine bone marrow culture-derived macrophages as mammalian host cell controls, compounds with anti-leishmanial activity showed moderate ( $\mathrm{EC}_{50} 25.0 \mu \mathrm{g} / \mathrm{mL}$ ) to pronounced ( $\mathrm{EC}_{50} 10.0 \mu \mathrm{g} / \mathrm{mL}$ ) toxic effects [24]. Our study also verified that most of the naphthoquinones tested noticeably inhibited extracellular parasite growth ( $\mathrm{IC}_{50} 0.8-38.7 \mu \mathrm{M}$ ) of L. braziliensis.

While the mechanism of action of the naphthoquinones to kill these parasites is a matter of debate, biochemical experiments provide initial insights. For example, it known that at ovaquone interacts with cytochrome Bl-c in Plasmodium spp. as well as ubiquinone is can be the potential target of analogs of the coenzyme Q, such as naphthoquinones [25,26]. This theory supports the hypothesis by Croft and co-workers [27,28] wherein killing Leishmania through a series of previously tested 
monomeric naphthoquinones involves generating free radicals when the drug interacts with the respiratory chain. In addition, the bis-lawsone analogs exhibit leishmanicidal activity against L. donovani promastigotes (with the $\mathrm{IC}_{50}$ values ranging from 2 to $14 \mu \mathrm{M}$ ) and inhibit leishmanial DNA topoisomerase-I [29]. Moreover, Plyta et al. [30] showed that 1,4-naphthoquinones bearing at least one phenolic hydroxyl group are potent topoisomerase enzyme inhibitors. Therefore, we will continue this study to evaluate the inhibitory effects of theses analogs on topoisomerase of Leishmania as well as other validated chemotherapeutic target.

\section{Experimental Section}

\subsection{General Information}

All reagents and solvents were obtained from commercial suppliers and used without further purification. The reaction progress was monitored using thin layer chromatography on silica gel TLC aluminum sheets. The melting points were determined using a Kofler hot stage apparatus and are uncorrected. FTIR spectra were obtained in a BOMEM MB-Series 100 spectrophotometer or a Bruker IRS66 using KBr discs. The NMR spectra were recorded in a Varian Unity Plus 300 or Varian UNMRS 400 instrument. Elemental analyses were performed using a CE EA1110 CHNS-O analyzer.

\subsection{Chemistry}

General Procedure for the Synthesis of Compounds $\mathbf{3 a}-\mathbf{h}$

A solution of lawsone $(\mathbf{1}, 174 \mathrm{mg}, 1 \mathrm{mmol})$, the corresponding aldehyde $\mathbf{2 a}-\mathbf{h}(0.5 \mathrm{mmol}), \beta$-alanine $(15 \mathrm{mg})$ and $2.5 \mathrm{~mL}$ of glacial acetic acid was stirred at $50{ }^{\circ} \mathrm{C}$ in argon atmosphere and reflux system for periods of $90 \mathrm{~min}$ at $5 \mathrm{~h}$ according to aldehyde used (the progress of reaction was monitored by TLC). The isolation of the compounds was done by adding crushed ice followed (except for compounds $\mathbf{3 b}$ and $\mathbf{3 c}$ ) by vacuum filtration of the formed precipitates. The solids were washed with distilled water and dried at room temperature, and the compounds were pure enough as inspected by TLC and spectroscopic methods [16]. For compounds $\mathbf{3 b}$ and $\mathbf{3 c}$ after adding ice the mixture was extracted with ethyl acetate, dried with anhydrous sodium sulfate and the solvents removed under reduced pressure, followed by subsequent purification in chromatography column with silica gel as stationary phase and methylene chloride as mobile phase.

3,3'-(Methylene)-bis[2-hydroxy-1,4-naphthalenedione] (3a). Yield: 83\% yellow solid. mp: 229-232 ${ }^{\circ} \mathrm{C}$ dec. $\left(229^{\circ} \mathrm{C}\right)$ [31]. IR (KBr) $v_{\max } / \mathrm{cm}^{-1}: 3452,3070,1678,1610,1573,1458,1350,1323,1265,1215$, 975, 937, 771, 736, 466; ${ }^{1} \mathrm{H}-\mathrm{NMR}$ (DMSO-d6, $\left.300 \mathrm{MHz}\right) \delta 3.74$ (s, 2H), 7.78 (dt, 2H, J 7.5/1.8 Hz), $7.83\left(\mathrm{dt}, 2 \mathrm{H}, J\right.$ 7.5/1.5 Hz), 7.97 (m, 4H); ${ }^{13} \mathrm{C}-\mathrm{NMR}\left(\mathrm{DMSO}-d_{6}, 75.4 \mathrm{MHz}\right) \delta 17.9,122.0,125.7,125.9$, 129.9, 132.0, 133.2, 134.6, 155.1, 180.8, 183.6. Anal. Calcd. $\mathrm{C}_{21} \mathrm{H}_{12} \mathrm{O}_{6}$ : C, 70.00; H, 3.36. Found: C, $69.03 ; \mathrm{H}, 3.82$.

3,3'-(Hexylidene)-bis[2-hydroxy-1,4-naphthalenedione] (3b). Yield: 54\%, orange solid. mp: 205-208 ${ }^{\circ} \mathrm{C}$ dec. $\left(213^{\circ} \mathrm{C}\right)$ [32]. IR (KBr) $v_{\max } / \mathrm{cm}^{-1}: 3433,2928,2855,1667,1628,1585,1566,1458,1366,1281$, 953, 737; ${ }^{1} \mathrm{H}-\mathrm{NMR}\left(\mathrm{DMSO}-d_{6}, 300 \mathrm{MHz}\right) \delta 1.32(\mathrm{t}, 3 \mathrm{H}, J 6.6 \mathrm{~Hz}), 1.72(\mathrm{~m}, 6 \mathrm{H}), 3.05(\mathrm{~m}, 2 \mathrm{H}), 5.83(\mathrm{t}$, 
$1 \mathrm{H}, J 8.1 \mathrm{~Hz}), 8.17(\mathrm{dt}, 2 \mathrm{H}, J 7.5 / 1.5 \mathrm{~Hz}), 8.27$ (dt, 2H, $J 7.8 / 1.5 \mathrm{~Hz}), 8.38$ (dd, 2H, J 7.5/1.5 Hz), 8.46 (dd, $2 \mathrm{H}, J$ 7.8/1.5 Hz); ${ }^{13} \mathrm{C}-\mathrm{NMR}$ (DMSO- $\left.d 6,75.4 \mathrm{MHz}\right) \delta 14.0,22.1,27.6,28.8,29.1,31.4,123.7$, 125.0, 125.7, 130.6, 132.0, 133.1, 133.9, 162.6, 182.9, 183.6. Anal. Calcd. $\mathrm{C}_{26} \mathrm{H}_{22} \mathrm{O}_{6} .\left(2 \mathrm{H}_{2} \mathrm{O}\right)$ : C, 66.95; H, 5.63. Found: C, 68.96; H, 5.74.

3,3'-(2-Ethylbutylidene)-bis[2-hydroxy-1,4-naphthalenedione] (3c). Yield: 34\%, orange solid. mp 210-211 ${ }^{\circ} \mathrm{C}\left(169-170{ }^{\circ} \mathrm{C}\right)$ [33] IR (KBr) $v_{\max } / \mathrm{cm}^{-1}: 3438,2962,2930,1649,1597,1461,1364,1283$, 729; ${ }^{1} \mathrm{H}-\mathrm{NMR}$ (DMSO-d6, $\left.400 \mathrm{MHz}\right) \delta 0.71(\mathrm{t}, 6 \mathrm{H}, J 7.2 \mathrm{~Hz}), 1.16(\mathrm{~m}, 2 \mathrm{H}), 1.31(\mathrm{~m}, 2 \mathrm{H}), 2.8(\mathrm{~m}, 1 \mathrm{H})$, 5.20 (d, 1H, J 12.4 Hz), 7.63 (t, 2H, J 7.2 Hz), 7.72 (t, 2H, J 7.6 Hz), 7.84 ( d, 2H, J 7.6 Hz), 7.90 (d, $2 \mathrm{H}, J 7.6 \mathrm{~Hz}$ ); ${ }^{13} \mathrm{C}-\mathrm{NMR}$ (DMSO- $\left.d 6,75.4 \mathrm{MHz}\right) \delta 10.0,22.0,33.7,35.6,123.4,125.2,125.9,130.3$, 132.4, 132.8, 134.2, 160.6, 182.7, 183.5. Elemental Anal. Calcd. $\mathrm{C}_{26} \mathrm{H}_{22} \mathrm{O}_{6}$ : C, 72.55; H, 5.15. Found: C, 67.50; H, 5.40.

3,3'-(Phenylmethylene)-bis[2-hydroxy-1,4-naphthalenedione] (3d). Yield: 89\%, yellow solid. mp 215-217 ${ }^{\circ} \mathrm{C}\left(202-204{ }^{\circ} \mathrm{C}\right)[16]$. IR (KBr) $v_{\max } / \mathrm{cm}^{-1}: 3450,1674,1597,1570,1361,1284,1222,1111$, 1056, 729; ${ }^{1} \mathrm{H}-\mathrm{NMR}$ (DMSO-d6, $\left.300 \mathrm{MHz}\right) \delta 6.69(\mathrm{~s}, 1 \mathrm{H}), 7.11(\mathrm{~m}, 5 \mathrm{H}), 7.67(\mathrm{dt}, 2 \mathrm{H}, J$ 7.5/1.2Hz), $7.76(\mathrm{dt}, 2 \mathrm{H}, J$ 7.5/1.2 Hz), 7.88 (dd, 2H, $J$ 7.5/1.2 Hz), 7.97 (dd, 2H, J 7.5/ $1.2 \mathrm{~Hz})$; ${ }^{13} \mathrm{C}-\mathrm{NMR}$ (DMSO-d6, $100 \mathrm{MHz}) \delta 37.7,123.1,125.4,125.6,126.0,127.6,128.2,129.9,132.2,133.1,134.7$, 140.8, 156.3, 181.2, 183.5. Anal. Calcd. for $\mathrm{C}_{27} \mathrm{H}_{16} \mathrm{O}_{6}$ : C, 74.31; H, 3.70. Found: C, 74.16; H, 4.28.

3,3'-(4-Methoxyphenylmethylene)-bis[2-hydroxy-1,4-naphthalenedione] (3e). Yield: 93\%, yellow solid. mp 222-223 ${ }^{\circ} \mathrm{C}\left(220-222{ }^{\circ} \mathrm{C}\right)$ [16].IR (KBr) $v_{\max } / \mathrm{cm}^{-1}: 3394,1666,1639,1593,1512,1458,1361$, 1338, 1276, 1261, 1238, 1045, 1018, 721; ${ }^{1} \mathrm{H}-\mathrm{NMR}$ (DMSO- $\left.d 6,300 \mathrm{MHz}\right) \delta 3.69$ (s, 3H), 5.94 (s, 1H), 6.75 (d, 2H, J 8.7 Hz), 7.14 (d, 2H, 8.7 Hz), 7.77 (dt, 2H, J 7.5/1.5 Hz), 7.82 (dt, 2H, J 7.5/1.5 Hz), 7.92 (dd, 2H, $J$ 7.5/1.5 Hz), 7.98 (dd, 2H, $J 7.5 / 1.5 \mathrm{~Hz}$ ); ${ }^{13} \mathrm{C}-\mathrm{NMR}$ (DMSO-d6, $\left.75.4 \mathrm{MHz}\right) \delta 37.3,54.9$, 113.1, 123.6, 125.6, 126.1, 129.4, 129.9, 132.2, 132.7, 133.2, 134.7, 155.9, 157.3, 181.3, 183.7. Anal. Calcd. $\mathrm{C}_{28} \mathrm{H}_{18} \mathrm{O}_{7}$ : C, 72.10; H, 3.89. Found: C, 70.49; H, 3.98 .

3,3'-(4-Hydroxyphenylmethylene)-bis[2-hydroxy-1,4-naphthalenedione] (3f). Yield: 98\%, yellow solid. mp $175-176{ }^{\circ} \mathrm{C}\left(175-177{ }^{\circ} \mathrm{C}\right)$ [16]. IV (KBr) $v_{\max } / \mathrm{cm}^{-1}: 3352,1647,1593,1512,1458,1365,1276$, 1045, 1010, 972, 902, 725; ${ }^{1} \mathrm{H}-\mathrm{NMR}$ (DMSO-d6, $\left.300 \mathrm{MHz}\right) \delta 5.92(\mathrm{~s}, 1 \mathrm{H}), 6.58$ (d, 2H, $\left.J 8.7 \mathrm{~Hz}\right), 7.01$ (d, 2H, $J 8.7 \mathrm{~Hz}), 7.76$, (dt, 2H, $J 7.5 / 1.2 \mathrm{~Hz}), 7.81$ (dt, $2 \mathrm{H} J 7.5 / 1.8 \mathrm{~Hz}), 7,92$ (dd, 2H, $J 7.5 / 1.2 \mathrm{~Hz}$ ), 7.97 (dd, 2H, J 7.5/1.8 Hz); ${ }^{13} \mathrm{C}-\mathrm{NMR}$ (DMSO-d6, 75.4 MHz) $\delta 37.2,114.6,123.8,125.6,126.8$, 129.3, 129.8, 130.8, 132.2, 133.2, 134.7, 155.3, 155.9, 181.3, 183.9. Anal. Calcd. $\mathrm{C}_{27} \mathrm{H}_{16} \mathrm{O}_{7}\left(2 \mathrm{H}_{2} \mathrm{O}\right): \mathrm{C}$, 66.40; H, 4.14. Found: C, 67.91; H, 4.38.

3,3'-(4-Nitrophenylmethylene)-bis[2-hydroxy-1,4-naphthalenedione] (3g). Yield: 92\%, yellow solid. mp 143-146 ${ }^{\circ} \mathrm{C} .\left(177-179{ }^{\circ} \mathrm{C}\right)$ [16]. IR (KBr) $v_{\max } / \mathrm{cm}^{-1}: 3433,2924,1670,1597,1570,1512,1350,1280$, 111, 732; ${ }^{1} \mathrm{H}-\mathrm{NMR}$ (DMSO-d6, $\left.300 \mathrm{MHz}\right) \delta 6.08(\mathrm{~s}, 1 \mathrm{H}), 7.53(\mathrm{~d}, 2 \mathrm{H} J 6.3 \mathrm{~Hz}$ ), $7.78(\mathrm{dt}, 2 \mathrm{H}$ $J 5.7 / 0.9 \mathrm{~Hz}), 7.83(\mathrm{dt}, 2 \mathrm{H}, J 5.7 / 0.9 \mathrm{~Hz}) 7.93(\mathrm{dd}, 2 \mathrm{H}, J 5.7 / 0.9 \mathrm{~Hz}), 8.00$ (dd, 2H, $J 5.7 / 0.9 \mathrm{~Hz}), 8.07$ $\left(\mathrm{d}, 2 \mathrm{H}, J\right.$ 6.6 Hz); ${ }^{13} \mathrm{C}-\mathrm{NMR}$ (DMSO-d6, 75.4 MHz) $\delta 37.6,121.8,122.8,125.7,126.1,129.3,130.0$, 132.2, 133.2, 134.7, 145.5, 150.0, 156.9, 181.2, 183.3. Anal. Calcd. $\mathrm{C}_{27} \mathrm{H}_{15} \mathrm{NO}_{8}: \mathrm{C}, 67.36 ; \mathrm{H}, 3.14 ; \mathrm{N}$, 2.91. Found: C, 65.79; H, 3.63; N, 3.63. 
3,3'-(4-Fluorophenylmethylene)-bis [2-hydroxy-1,4-naphthalenedione] (3h). Yield: 83\%, yellow solid. mp 202-204 ${ }^{\circ} \mathrm{C}\left(193-195{ }^{\circ} \mathrm{C}\right)$ [14]. IR (KBr) $v_{\max } / \mathrm{cm}^{-1}: 3414,3348,1666,1625,1593,1508,1458$, 1365, 1342, 1276, 1230, 1161, 1041, 833, 725; ${ }^{1} \mathrm{H}-\mathrm{NMR}$ (DMSO-d6, $\left.400 \mathrm{MHz}\right) \delta 6.00$ (s, 1H), 7.00 (m, 2H), $7.28(\mathrm{~m}, 2 \mathrm{H}), 7.77(\mathrm{~m}, 4 \mathrm{H}), 7.91(\mathrm{~d}, 2 \mathrm{H}, J 7.2 \mathrm{~Hz}), 7.97$ (d, 2H, 6.4 Hz); ${ }^{13} \mathrm{C}-\mathrm{NMR}$ (DMSO-d6, $100 \mathrm{MHz}) \delta 37.7,114.5,123.5,126.0,126.5,130.3,132.6,133.5,135.1,137.4,156.5,159.8,162.2$, 181.6, 184.0. Anal. Calcd. $\mathrm{C}_{27} \mathrm{H}_{15} \mathrm{FO}_{6}$ : C, 71.37; H, 3.33. Found: C, 71.16; H, 3.44.

\subsection{Biological Evaluation of Naphthoquinones}

\subsubsection{Parasite Culture}

L. braziliensis promastigotes (MHOM/BR/87/BA788) were obtained from Dra. Valéria de Matos Borges at the Gonçalo Moniz Research Center, Fiocruz_BA. L. amazonensis promastigotes (MHOM/BR/77/LTB0016) were obtained from Dr. Eduardo Caio Torres dos Santos at the Oswaldo Cruz Institute-Fiocruz_RJ. The parasites were maintained in vitro in Schneider's medium supplemented with $10 \% \mathrm{FBS}$ and $2 \%$ human urine at $27^{\circ} \mathrm{C}$ in BOD incubator.

\subsubsection{J774.A1 Murine Macrophage Culture}

The adherent-phenotype macrophage line was cultured in Dulbecco's Modified Eagle's medium (DMEM, Sigma, Dublin, Ireland) supplemented with $10 \% \mathrm{FBS}$ at $37{ }^{\circ} \mathrm{C}, 95 \%$ humidity and $5 \% \mathrm{CO}_{2}$.

\subsubsection{Cytotoxicity against Host Cells}

To evaluate the cytotoxicity activity against the $\mathrm{J} 774$ cell line, the host cells were plated in 96-well vessels at $2 \times 10^{5}$ cells per well in a complete culture medium with $10 \% \mathrm{FBS}$ at $37^{\circ} \mathrm{C}$. After $1 \mathrm{~h}$, the wells were washed with HBSS to remove non-adherent cells, leaving approximately $1 \times 10^{5}$ adherent macrophages. The cells were cultured in DMEM complete medium supplemented with $10 \%$ FBS. The compounds and pentamidine were added at serial concentrations $(0.1-100 \mu \mathrm{M})$. The cells were also cultured in media free from compounds, a vehicle (basal growth control) or media with DMSO $0.1 \%$ (vehicle control). The positive control (dead cells) was obtained through cellular lyses with $1 \%$ of Triton X-100 in DMEM complete medium. After $48 \mathrm{~h}$, the cytotoxicity was evaluated using the MTT assay [34]. The data obtained from the experiments were expressed as the mean \pm S.E.M., and the significant differences between the treated and vehicle groups were evaluated using ANOVA and Dunnett post-hoc tests.

\subsubsection{In Vitro Activity against L. braziliensis and L. amazonensis}

The parasites were maintained in vitro in Schneider's medium supplemented with 10\% FBS and 2\% human urine. Novel bis-lawsone analog stock solutions and pentamidine (reference leishmanicidal drug) were prepared in DMSO immediately before use. The cytotoxicities of the bis-lawsone analogs and pentamidine against the promastigotes were determined. Stationary phase L. braziliensis and L. amazonensis promastigotes were plated in 96-well vessels (Nunc, Roskilde, Denmark) at $1 \times 10^{5}$ cells per well in Schneider's medium supplemented with 10\% FBS and 2\% human urine. Each 
compound solution was added at increasing concentrations $(0.1-100 \mathrm{mg}$ to the extract and its phases or 0.1-100 $\mu \mathrm{M}$ to the isolates and pentamidine). The cells were also cultured in a medium free of compounds, a vehicle (basal growth control) or with DMSO $0.1 \%$ (vehicle control). After $48 \mathrm{~h}$, the extracellular load for L. braziliensis and L. amazonensis promastigotes was estimated by counting the promastigotes in Schneider's medium using a CELM automatic cell counter (model CC530, Barueri, Brazil) [35]. The data obtained from experiments were expressed as the mean \pm S.E.M., and the significant differences between the treated and vehicle groups were evaluated using ANOVA and Dunnett post-hoc tests.

\subsubsection{In Vivo Activity against Leishmania amazonensis}

This study was approved (protocol no. 2013.02) by the Ethics Committee for Animal Experimentation of the Federal University of Alagoas (Brazil). All animals received humane care in compliance with the "Principles of laboratory animal care" formulated by the National Society for Medical Research and the "Guide for the care and use of laboratory animals" prepared by the National Academy of Sciences (Washington, DC, USA). Next, $1 \times 10^{5}$ stationary promastigotes ( 5 days of culture in Schneider's medium) of L. amazonensis (MHOM/BR/77/LTB0016) were subcutaneously inoculated into the right ear dermis of 6-week-old female BALB/c mice weighing $c a .20 \mathrm{~g}$. and were later intraperitoneally treated with $3 \mathrm{a}$ or glucantime at $30 \mu \mathrm{mol} / \mathrm{kg} \times 28$ days. The lesion size was measured using a paquimeter [36]. The parasite loads of infected ears and draining lymph nodes were determined using a quantitative limiting-dilution assay [37]. Complex toxicity was also evaluated through biochemistry dosages in plasma. The experimental data were expressed as the mean \pm S.E.M., and the significant differences between the treated and vehicle groups were evaluated using ANOVA and Dunnett post-hoc tests.

\subsubsection{In Silico Screening}

Bis-lawsone analogs were submitted to in silico screening using the program OSIRIS [18] to analyze their overall drug score and drug likeness potential as well as toxicity risks (mutagenic, irritant, tumorigenic and reproductive effects) [19] of the bis-lawsone analogs.

\section{Conclusions}

The present study reports the synthesis and leishmanicidal evaluation of a series of substituted bis-2-hydroxy-1,4-naphthoquinones prepared from lawsone. The in vitro cytotoxic activities of the derivatives synthesized were evaluated against $L$. braziliensis, where they showed a maximum effect greater than $60 \%$. The bis-lawsone analogs $3 \mathbf{a}, \mathbf{3 b}, \mathbf{3 e}$ and $\mathbf{3 h}$ present efficacies and potencies similar to the reference drug pentamidine without cytotoxicity to the host cells. Finally, 3a presented the activity $30 \mu \mathrm{mol} / \mathrm{kg} \times 28$ days (i.p.); the L. amazonensis lesion size on the infected ear of BALB/c mice decreased, but the number of parasites in the infected ear and draining lymph nodes did not decrease. In summary, these findings show that $\mathbf{3 a}, \mathbf{3 e}$ and $\mathbf{3 h}$ are antileishmanial drug candidates and suggest a useful starting point for rationally designing new agents against leishmaniasis. Clearly, 
further studies are necessary for exciting advances in the medicinal use of drug candidates in this class of secondary products.

\section{Supplementary Materials}

Supplementary materials can be accessed at: http://www.mdpi.com/1420-3049/19/9/15180/s1.

\section{Acknowledgments}

The authors are grateful to the CAPES, MCT, FINEP, FACEPE-PRONEM (APQ-1232-1.06/10), CENAPESQ, FAPEAL (Pronem 20110722-006-0018-0010), CNPQ (479822/2013-1), CNPQ (404344/2012-7), INCT-INOFAR/CNPq (573.564/2008-6) for the joint funding of this research project. The authors wish to thank several of their colleagues working at the Federal University of Alagoas for their constructive criticism and assistance in carrying out this project.

\section{Author Contributions}

Conceived and designed the experiments: MVA, ACQ, CBBM. Performed the experiments: MVA, ACQ, CBBM, ABL, AES, PSOS. Analyzed the data: MVA, ACQ, PSOS, JAAF, MSA-M. Contributed reagents/materials/analysis tools: PSOS, JAAF, MSA-M, TMSS, CAC. Wrote the paper: MVA, ACQ, MSA-M, TMSS, CAC.

\section{Conflicts of Interest}

The authors declare no conflict of interest.

\section{References}

1. Benítez, J.; Valderrama, J.A.; Rivera, F.; Rojo, L.; Campos, N.; Pedro, M.; Nascimento, M.S.J. Studies on quinones. Part 42: Synthesis of furylquinone and hydroquinones with antiproliferative activity against human tumor cell lines. Bioorg. Med. Chem. 2008, 16, 862-868.

2. Araújo, A.J.; de Souza, A.A.; da Silva-Júnior, E.N.; Marinho-Filho, J.D.B.; de Moura, M.A.B.F.; Rocha, D.D.; Vasconcellos, M.C.; Costa, C.O.; Pessoa, C.; de Moraes, M.O.; et al. Growth inhibitory effects of 3'-nitro-3-phenylamino nor-beta-lapachone against HL-60: A redox-dependent mechanism. Toxicol. In Vitro 2012, 26, 585-594.

3. Barbosa, T.P.; Camara, C.A.; Silva, T.M.S.; Martins, R.M.; Pinto, A.C.; Vargas, M.D. New 1,2,3,4-tetrahydro-1-aza-anthraquinones and 2-aminoalkyl compounds from nor-lapachol with molluscicidal activity. Bioorg. Med. Chem. 2005, 13, 6464-6469.

4. Teixeira, M.J.; de Almeida, Y.M.; Viana. J.R.; Filha, J.G.H.; Rodrigues, T.P.; Prata, J.R.C., Jr.; Coêlho, I.C.B.; Rao, V.S.; Pompeu, M.M.L. In vitro and in vivo Leishmanicidal activity of 2-hydroxy-3-(3-methyl-2-butenyl)-1,4-naphthoquinone (lapachol). Phytother. Res. 2001, 15, 44-48.

5. Ali, A.; Assimopoulou, A.N.; Papageorgiou, V.P.; Kolodziej, H. Structure/antileishmanial activity relationship study of naphthoquinones and dependency of the mode of action on the substitution patterns. Planta Med. 2011, 77, 2003-2012. 
6. Gafner, S.; Wolfender, J.L.; Nianga, M.; Stoeckli-Evans, H.; Hostettmann, K. Antifungal and antibacterial naphthoquinones from Newbouldia laevis roots. Phytochemistry 1996, 42, 1315-1320.

7. Antunes, R.M.P.; Lima, E.O.; Pereira, M.S.V.; Camara, C.A.; Arruda, T.A.; Catão, R.M.R.; Barbosa, T.P.; Nunes, X.P.; Dias, C.S.; Silva, T.M.S. Atividade antimicrobiana "in vitro" e determinação da concentração inibitória mínina (CIM) de fitoconstituintes e produtos sintéticos sobre bactérias e fungos leveduriformes. Braz. J. Pharmacogn. 2006, 16, 517-524.

8. Da Silva Júnior, E.N.; de Melo, I.M.M.; Diogo, E.B.T.; Costa, V.A.; Filho, J.D.S.; Valença, W.O.; Camara, C.A.; de Oliveira, R.N.; Araújo, A.S.; Emery, F.S.; et al. On the search for potential anti-Trypanosoma cruzi drugs: synthesis and biological evaluation of 2-hydroxy-3-methylamino and 1,2,3-triazolic naphthoquinoidal compounds obtained by click chemistry reactions. Eur. J. Med. Chem. 2012, 52, 304-312.

9. Stagliano, K.W.; Emadi, A.; Lu, Z.; Malinakova, H.C.; Twenter, B.; Yu, M.; Holland, L.E.; Rom, A.M.; Harwood, J.S.; Amin, R.; et al. Regiocontrolled synthesis and HIV inhibitory activity of unsymmetrical binaphthoquinone and trimeric naphthoquinone derivatives of conocurvone. Bioorg. Med. Chem. 2006, 14, 5651-5665.

10. Krishnan, P.; Bastow, K.F. Novel mechanism of cellular DNA topoisomerase II inhibition by the pyranonaphthoquinone derivatives alpha-lapachone and beta-lapachone. Cancer Chemother. Pharmacol. 2001, 47, 187-198.

11. Da Silva, M.N.; Ferreira, V.F.; de Souza, M.C.B.V. Um panorama atual da química e da farmacologia de naftoquinonas, com ênfase nab-lapachona e derivados. Quim. Nova 2003, 26, 407-416.

12. Ferreira, S.B.; Gonzaga, D.T.G.; Santos, W.C.; Araújo, K.G.L.; Ferreira, V.F. $\beta$-Lapachona: Sua importância em química medicinal e modificações estruturais. Rev. Virtual Quim. 2010, 2, 140-160.

13. Patil, R.S.; Patil, M.S.; Kshirsagar, S.S.; Chaudhari, P.S.; Bayas, J.P.; Oswal, R.J. Synthetic and natural products against leishmaniasis: A review. World J. Public Health Sci. 2012, 1, 7-22.

14. Li, Y.; Du, B.; Xu, X.; Shi, D.; Ji, S. A green and efficient synthesis of 13-Aryl-5,7,12,14tetrahydrodibenzo[ $b, i]$ xanthene-5,7,12,14(13H)-tetraone derivatives in ionic liquid. Chin. J. Chem. 2009, 27, 1563-1568.

15. Tisseh, Z.N.; Azimi, S.C.; Mirzaei, P.; Bazgir, A. The efficient synthesis of aryl-5H-dibenzo[b,i]xanthene-5,7,12,14(13H)-tetraone leuco-dye derivatives. Dyes Pigm. 2008, $79,273-275$.

16. Tisseh, Z.N.; Bazgir, A. An efficient, clean synthesis of 3,3'-(arylmethylene)bis(2hydroxynaphthalene-1,4-dione) derivatives. Dyes Pigm. 2009, 83, 258-261.

17. Mazumder, A.; Wang, S.; Neamati, N.; Nicklaus, M.; Sunder, S.; Chen, J.; Milne, G.W.A.; Rice, W.G.; Burke, T.R., Jr.; Pommier, Y. Antiretroviral agents as inhibitors of both human immunodeficiency virus type 1 integrase and protease. J. Med. Chem. 1996, 39, 2472-2481.

18. OSIRIS Property Explorer. Available online: http://www.organic-chemistry.org/prog/peo/ (accessed on 14 April 2014).

19. Sander, T.; Freyss, J.; von Korff, M.; Reich, J.R.; Rufener, C. OSIRIS, an entirely in-house developed drug discovery informatics system. J. Chem. Inf. Model. 2009, 49, 232-246. 
20. Moore, H. Bioactivation as a model for drug design bioreductive alkylation. Science 1977, 197, $527-532$.

21. World Health Organization (WHO). Leishmaniasis. Available online: http://www.who.int/ leishmaniasis/en/ (accessed on 19 July 2013).

22. Marr, A.K.; Mc Gwire, B.S.; Mc Master, W.R. Modes of action of Leishmanicidal antimicrobial peptides. Future Microbiol. 2012, 7, 1047-1059.

23. Lima, N.M.F.; Correia, C.S.; Leon, L.L.; Machado, G.M.C.; Madeira, M.F.; Santana, A.E.G.; Goulart, M.O.F. Antileishmanial activity of lapachol analogues. Mem. Inst. Oswaldo Cruz 2004, 99, 757-761.

24. Kayser, O.; Kiderlen, A.F.; Laatsch, H.; Croft, S.L. In vitro leishmanicidal activity of monomeric and dimeric naphthoquinones. Acta Trop. 2000, 77, 307-314.

25. Fry, M.; Pudney, M. Site of action of the antimalarial hydroxynaphthoquinone, 2-[trans-4-(4'chlorophenyl) cyclohexyl]-3-hydroxy-1,4-naphthoquinone (566C80). Biochem. Pharmacol. 1992, $43,1545-1553$.

26. Ellis, J.E. Coenzyme Q homologs in parasitic protozoa as targets for chemotherapeutic attack. Parasitol. Today 1994, 10, 296-301.

27. Croft, S.L.; Evans, A.T.; Neal, R.A. The activity of plumbagin and other electron carriers against Leishmania donovani and Leishmania mexicana amazonensis. Ann. Trop. Med. Parasitol. 1985, 79, 651-653.

28. Croft, S.L.; Hogg, J.; Gutteridge, W.E.; Hudson, A.T.; Randall, A.W.J. The activity of hydroxynaphthoquinones against Leishmania donovani. Antimicrob. Chemother. 1992, 30, 827-832.

29. Sharma, G.; Chowdhury, S.; Sinha, S.; Majumder, H.K.; Kumar, V.J. Antileishmanial activity evaluation of bis-lawsone analogs and DNA topoisomerase-I inhibition studies. Enzym. Inhib. Med. Chem. 2004, 2, 185-189.

30. Plyta, Z.; Li, T.; Papageorgiou, V.; Mellidis, A.; Assimopoulou, A.; Pitsinos, E.; Culadouros, E. Inhibition of topoisomerase I by naphthoquinone derivatives. Bioorg. Med. Chem. Lett. 1998, 8, 3385-3390.

31. Panichayupakaranant, P.; Noguchi, H.; De-Eknamkul, W.; Sankawa, U. Naphthoquinones and coumarins from Impatiens balsamina root cultures. Phytochemistry 1995, 40, 1141-1143.

32. Nagabhushana, K.S.; Ameer, F.; Green, I.R. Condensation products between caproaldehyde and 2-hydroxy-1,4-naphthoquinone. Syn. Commun. 2001, 31, 719-724.

33. Bock, K.; Jacobsen, N.; Terem, B. Reaction of 2-hydroxy-1,4-naphthoquinone with aldehydes. Synthesis of 2-hydroxy-3-(1-alkenyl)naphthoquinones. J. Chem. Soc. Perkin Trans. 1 1986, 1986, 659-664.

34. Hussain, R.F.; Nouri, A.M.; Oliver, R.T. A new approach for measurement of cytotoxicity using colorimetric assay. J. Immunol. Methods 1993, 160, 89-96.

35. Rangel, H.; Dagger, F.; Hernandez, A.; Liendo, A.; Urbina, J.A. Naturally azole-resistant Leishmania braziliensis promastigotes are rendered susceptible in the presence of terbinafine: comparative study with azole-susceptible Leishmania mexicana promastigotes. Antimicrob. Agents Chemother. 1996, 40, 2785-2791. 
36. Pereira, J.C.; Carregaro, V.; Costa, D.L.; da Silva, J.S.; Cunha, F.Q.; Franco, D.W. Antileishmanial activity of ruthenium(II)tetraammine nitrosyl complexes. Eur. J. Med. Chem. 2010, 45, 4180-4187.

37. Taswell, C. Limiting dilution assays for the separation, characterization and quantification of biologically active particles and their clonal progeny. In Cell Separation: Methods and Selected Applications; Pretlow, T.C., Pretlow, T.P., Eds.; Academic Press: New York, NY, USA, 1986; pp. 109-145.

Sample Availability: Samples of the compounds $\mathbf{3 a}-\mathbf{h}$ are available from the authors.

(C) 2014 by the authors; licensee MDPI, Basel, Switzerland. This article is an open access article distributed under the terms and conditions of the Creative Commons Attribution license (http://creativecommons.org/licenses/by/3.0/). 